\title{
MERAYAKAN SIWARATRI: \\ MEMBANGUN KESADARAN MULTIKULTUR DALAM PLURALISME \\ AGAMA \\ (PERSPEKTIF KAJIAN BUDAYA)
}

\author{
Ervantia Restulita L. Sigai ${ }^{I}$
}

\begin{abstract}
Religion is often expressed as a binding force while preserving the potential conflicts. The religion has a central role in the institution of life and provides inner comfort for its adherents. Siwaratri is a Hindu ritual practice. On the micro scale, it is the symbol of Sang Hyang Widhi Wasa/Ranying Hatalla Langit. Then, on the macro scope its builds awareness of multiculture.
\end{abstract}

Keyword: siwaratri, self-awareness, multicultural

\begin{abstract}
Abstrak
Agama sering dinyatakan sebagai kekuatan yang mengikat sambil menjaga potensi konflik. Agama memiliki peran sentral dalam institusi kehidupan dan memberikan kenyamanan batin bagi penganutnya. Siwaratri adalah praktik ritual Hindu. Pada skala mikro, itu adalah simbol Sang Hyang Widhi Wasa / Ranying Hatalla Langit. Kemudian, pada lingkup makro membangun kesadaran multikultur.
\end{abstract}

Kata kunci: siwaratri, kesadaran diri, multikultural

${ }^{1}$ Penulis adalah Dosen Jurusan Dharma Duta STAHN-TP Palangka Raya 


\section{Pendahuluan}

Epstain (1995: 280) menyatakan budaya adalah suatu bentuk kompensasi terhadap entitas kita yang tidak komplit, tidak ada entitas yang benar-benar komplit, sehingga perlu untuk merestorasi presepsi kultural. Kecenderung menganggap budaya sendiri sebagai suatu kemestian, tanpa mempersoalkan lagi (taken-forgranted), dan karenanya kita menggunakannya sebagai standar untuk mengukur budaya-budaya lain (Mulyana, 2005: vii). Bagaimana memfasilitasi interaksi damai dan kooperatif dalam suatu masyarakat bilamana para warganya tidak memiliki perasaan mengenai diri sendiri sebagai suatu bangsa atau sebuah budaya (Hefner, 2007: 17).

Tiga unsur sosial-kultural mempunyai pengaruh besar dan langsung atas makna-makna yang kita bangun dari pesepsi kita. Unsur-unsur tersebut adalah sistem kepercayaan (belief), nilai (value), sikap (attitude), pandangan dunia (world view), dan organisasi sosial (social organization). Kelima unsur utama ini mempengaruhi persepsi dan makna yang dibangun dalam persepsi. Unsur-unsur tersebut mempengaruhi aspek makna yang bersifat pribadi dan subjektif (Mulyana, 2005 : $24-26$ ). M e 1 a 1 u i Pendidikan/edukasi akan didapat aspek yang bersifat subjektif dan dapat dipahami sebagai keberbedaan/ multikulturalisme yang saling melengkapi. Lewat komunikasi lintas budaya yang intensif dapat memupus konflik secara gradatif menciptakan saling kesepahaman dan transkulture (Sigai, 2007: 177).

Salah satu faktor determinan terkait dengan persoalan integrasi adalah masalah agama. Agama sering kali dinyatakan sebagai kekuatan pengikat sekaligus menyimpan potensi konflik, mengingat negeri ini terdiri dari banyak agama baik secara formal maupun non formal (agama suku) (Kaler, dkk, 2003: 348). Lebih lanjut Kaler dan Wiasti (2003: 348-349) menyatakan, sebagai sumber normatif dan moralitas, agama menempatkan posisi sentral dalam kehidupan sosio-kultural dan memberikan kenyamanan batin serta rasa damai bagi para pemeluknya. Akan tetapi, karena setiap agama menyatakan kebenaan ajarannya dan merasa berkewajiban menyebarluaskan ajarannya maka tidak mustahil dapat menimbulkan salah pengertian dan prasangka antara pemeluk agama satu dengan yang lainnya dalam kerangka kehidupan bermasyarakat dan bernegara. Situasi seperti ini dapat memicu hubungan tidak sehat dan merugikan dalam usaha pembinaan integrasi umumnya serta menciptakan kerukunan hidup antar umat beragama khususnya. 
Arena pertarungan terjadi akibat berbagai asumsi yang mengklaim bahwa kebenaran hanya dimiliki kaum mayoritas, sedangkan kelompok minoritas dianggap sesat (Sigai, 2016a: 287). Seorang individu akan bersikap dan bertindak sesuai dengan cara-cara yang berlaku dan yang diharapkan oleh golongannya. Dalam situasi konflik seorang individu akan menyesuaikan diri dengan peranan yang diharapkan oleh golongannya itu, yang oleh Dahrendorf disebut sebagai peranan laten.

Perbedaan hendaknya tidak menjadi dasar esklusif orang lain untuk membentuk identitas diri sendiri. Perbedaan harus memungkinkan setiap orang untuk tetap memeluk keyakinannya tanpa harus memperdebatkan perbedaan keyakinan orang lain. Membicarakan kerukunan agama maupun toleransi bukan sekedar jargon yang menjadi objek pembicaraan secara teoritis demi mempertahankan kekuasaan dan status qou, namum nihil secara praktek. Hal yang pokok yang perlu dipahami lebih dulu bagaimana memahami ajaran agama masingmasing. Menjalani ajaran agama membangun mental spiritual. Di dalam ajaran Hindu menjalankan Siwaratri untuk membuka kesadaran dan evaluasi diri membuka salah satu aspek jalan bagi jiwa yang toleran dan berinegrasi. Pembahasan persoalan kesadaraan spritualitas dalam konteks kekinian sangat relevan diangkat kepermukaan seiring dengan perubahaan yang terjadi dalam kehidupan beragama dan berbangsa.

\section{Pembahasan}

Pada era globalisasi ini, seringkali munculnya tuntunan yang berlebihan baik dalam skala lokal maupun skala nasional, bahkan tidak jarang menjadi persoalan krusial yang dapat mengancam desintegrasi bangsa disebabkan sentiment agama dan pandangan yang paranoid terhadap agama orang lain yang dianggap tidak selaras dengan keyakinannya. Terjadi rezimentasi atas kebenaran beragama yang pada gilirannya mengklaim bahwa merekalah yang memiliki kebenaran yang sejati sekaligus mengupayakan suatu legitimasi untuk melakukan tindakan-tindakan yang diperlukan dalam menjaga integritas beragama (Sigai, 2016a: 284).

Ideologi ketuhanan yang berbeda tidak dapat digunakan untuk menghakimi keyakinan yang berbeda. $\mathrm{M}$ engatas namakan agama dan menjadikannya arena pertarungan. Sering 'baju agama' digunakan dan dimanfaatkan orang untuk menghegemoni dan menindas yang lainnya. Prilaku tersebut memperoleh legitimasi kuasa dari kelompoknya. Prasangka atau asumsi yang bertolak 
dari keyakinan, kepercayan, dan agama merupakan salah satu prasangka yang berbentuk universal. Menurut Taylor, Peplau, Sears (2009: 213) prasangka merupakan komponen afektif atau komponen evaluatif dari antagonisme kelompok. Prasangka merupakan sikap sosial atau keyakinan kognitif yang merendahkan, mengekspresiakan perasaan negatif atau tindakan bermusuhan dan diskriminatif.

Suatu prasangka muncul dan berkembang dikontruksikan dari satu individu ke individu lain atau terhadap kelompok ke kelompok tertentu, ketika seseorang tersebut berbeda dengan dirinya. Menguratkan term 'kekitaan', 'kekamian', term ini menyangkut dikotomi 'kami' dan 'mereka' pembedaan atas klaim kebenaran. Jean Paul Satre (dalam Abdilah, 2002: 78) mengungkapkan bahwa relasi itu dibangun atas dasar distings antara 'aku' dan 'orang lain' (the other), lebih luas lagi 'kami' dan 'mereka'. Di sini, 'orang asing' merupakan hasil konstruksi sosial berdasarkan situasi dan konteks tertentu.

Intoleran agama terlalu sering dilihat secara dangkal (superficial) yang dasarnya perbedaan identitas dasar yang mengejawantah pada sindrom 'kitamereka'. Sering prasangka-prasangka tersebut muncul dari kalangan elit agama tertentu. Sebagaimana pernyataa Weber (dalam Sanderson, 2011: 529) melihat agama melakukan fungsi-fungsi yang sangat berbeda untuk berbagai strata sosial. Bagi strata sosial yang $\mathrm{m}$ empunyai hak-hak istimewa, ditandaskannya bahwa agama terutama berfungsi sebagai suatu alat untuk melegitimasi atau membenarkan posisi sosial mereka yang berkuasa dan memiliki hak-hak istimewa kelas.

$\mathrm{K}$ e h i d u p a n s o s i a 1 antarkomunitas antarkeyakinan terjadi proses persaingan, kerjasama dan konflik memang tak terelakan dalam d unia global. Pola hubungan antarindividu maupun kelompok sosial masyarakat dengan berbagai kepentingan, maka pergesekan kepentingan akan menimbulkan konflik di antara mereka disebabkan oleh cara pandang yang berbeda terhadap peristiwa tertentu. Prasangka, asumsi dan penghujatan dapat melahirkan partisipan konflik yang meluas dan menimbulkan konflik laten yang termanifestasikan dalam wujud sikap dan tindakan yang dikemudian hari akan menjadi bumerang bagi integrasi keberagamaan (Sigai, 2016a: 289).

Apabila dicermati konflik terjadi karena kesalahpahaman akibat pertentangan antara harapan, standar normatif dan hubungan yang tertutup. Menurut Dahrendorf (dalam Poloma, 2000: 138) hubungan yang tertutup dapat berakibat terjadi konflik terselubung di antara mereka karena adanya saling tidak percaya dan 
berbagai kepentingan lainnya. Namun, konflik bisa saja konflik yang dipelihara, dikontruksi untuk kepentingankepentingan tertentu. Menurut Bourdieu, praktik individu dan sosial merupakan hasil interaksi ranah dan habitus yang dapat dipahami melalui perjuangan posisi-posisi dalam ranah (Harker, dkk, 2009: 19).

Fenomena konflik tersebut akan sering terjadi, jika semua elemen bangsa tidak menghargai dan mengedepankan semangat toleransi, semangat persaudaraan dan semangat persatuan yang dilandasi semangat Bhinneka Tunggal Ika. Oleh sebab itu diperlukan upaya agar keragaman agama menjadi sebuah "kekayan dan kekuatan" yang harus tetap terjaga dalam masyarakat. Gagasan multikultural bukan merupakan suatu yang abstrak tetapi pengembangan suatu pola tingkah laku yang hanya dapat diwujudkan melalui kesadaraan diri. Stavenhagen (1996), multikultural mengakui adanya keragaman etnik dan budaya masyarakat suatu bangsa menyatakan,

Religious, linguistic, and national minoritas, as well as indigenous and tribal peoples were often subordinated, sometimes forcefully and against their will, to the interest of the state and the dominant society. While many people... had to discard their own cultures, languages, religions and traditions, and adapt to the alien norms and customs that were consolidated and reproduced through national institutions, including the educational and legal system.

Selain itu, multikulturalisme tidak akan berhenti pada pengakuan akan identitas suatu kelompok masyarakat tetapi ditunjukan terwujudnya integrasi nasional melalui budaya yang beraneka ragam (Tilaar, 2003:167). Racheal Kessler (dalam Megawangi, 2005) secara gamblang menekankan pentingnya aspek spiritual dalam proses pendidikan, karena sistem pendidikan selama ini telah mengabaikan aspek ini. Aspek spiritual ini akan membangun anak menjadi interconnection (santi); selaras baik d e $\mathrm{n}$ gan Sang Hyang Widhi Wasa/Ranying Hatalla Langit, manusia maupun alam; compassion (karuna), kasih sayang dan kepedulian. Mengajarkan kepada anak tentang kesadaraan bahwa setiap aspek dalam kehidupan saling terkait sehingga anak dapat menjalani kehidupan dan produktif, damai dan secara berkelanjutan karena setiap tindakan anak atau individu akan berdampak kepada lingkungan.

Tahapan proses transmisi tersebut identifikasi diri akan dibangun berorientasi pada kesadaraan tanggung jawab sosial kultural dalam masyarakat. Proses ditransmisikan secara subjektif ke dalam dirinya. Identitas agama, 
tradisi, dan pemahaman multikultural akan dikonseptualisasikan dalam kehidupan keluarga, lingkungan dan komunitasnya (Sigai, 2016b: 264).

Menurut Morris (dalam Suhardi, 2009: 1), bahwa agama adalah suatu institusi sosial, suatu sistem sosialbudaya dan bukan hanya dipandang sekedar sebagai ideologi atau suatu sistem kepercayaan. Tetapi sesungguhnya tindakan agama juga mencerminkan kesadaran manusia terhadap yang transeden. Suhardi (2009: 13--19) menyatakan bahwa ritual adalah agama dalam tindakan untuk mencari jalan keselamatan. Oleh karena itu, ritual pada hakikatnya memang memiliki fungsi religius. Parsudi Suparlan (dalam Rudito, 2013: ix-x) menyatakan agama dilihat sebagai doktrin dan teks, namun dalam menginterpretasikan dan memahami makna-makna yang terkandung dalam ajaran-ajaran di dalam teks suci, para pemeluk agama yang bersangkutan menggunakan kebudayaan mereka sebagai acuan. Sistem-sistem pengetahuan, kebudayaan atau hasil-hasil interpretasi menjadi keyakinaan keagamaan yang menjadi pedoman sakral atau suci dari kebudayaannya, atau bagi kehidupan mereka. Dengan kata lain, hasil interpretasi mereka yang terwujud sebagai keyakinan keagamaan tersebut menjadi kebudayaan yang telah mereka punyai.
Sebuah masyarakat adalah sebuah tatanan moral, yaitu seperangkap tuntunan normatif dalam kenyataan ideal daripada kenyataan material, yang ada dalam kesadaraan. Pemikiran Durkheim (dalam Campbell, 1980: 179) menyatakan dua dalil untuk menjelaskan kenyataan sosial, yaitu pertama, conscience collective (kesadaraan kolektif atau suara hati kolektif); kedua, representation collective (gambaran kolektif). Durkheim (dalam Campbell, 1980: 179180) menyatakan pula bahwa gambaran kolektif adalah simbol-simbol yang mempunyai makna yang sama bagi semua anggota yang membentuk sebuah sistem tertentu dan berfungsi mengatur $\mathrm{k}$ ehidupan dalam masyarakat.S edangkan kesadaraan kolektif mengandung semua gagasan yang dimiliki bersama oleh para anggota individual masyarakat yang menjadi tujuan-tujuan dan maksud-maksud kolektif. Dalam tataran ini kesadaraan kolektif adalah sebuah konsensus normatif yang mencakup kepercayaankepercayaan lain yang menyokong.

Kesadaran kolektif akan terbagun tidak hanya oleh tindakan represif "kekuasaan". Namun kesadaran kolektif bermula dari kesadaraan diri. Kesadaran diri dapat dibangun melalui Siwaratri. Hari raya Siwaratri dilaksanakan setahun sekali setiap purwaning tilem ke-tujuh. 
Siwaratri adalah hari suci untuk melaksanakan pemujaan ke hadapan Sang Hyang Widhi Wasa dalam perwujudan Sang Hyang Siwa, pada saat itu Sang Hyang Siwa beryoga. Sehubungan dengan itu umat Hindu melaksanakan kegiatan penyucian diri dan pikiran dalam usaha menimbulkan kesadaran diri. Kegiatan ritual Siwaratri (Bratha Siwaratri) meliputi: (1) persembahyangan pagi hari pukul 06.00, (2) monabrata, tidak berbicara/berdiam diri (16 jam dari Pukul 06.00-18.00) (3) mejagra, tidak tidur (36 jam dari pukul 06.00-18.00 keesokan harinya) dan (4) upawasa, tidak makan dan minum puasa (24 jam dari pukul 06.00-06.00, jika telah sampai 12 jam diperbolehkan makan dan minum dengan nasi putih, garam dan minum air putih). Pelaksanaan ritual Siwaratri terdiri dari tingkatan tertentu yang disesuiakan dengan kemampuan diri seseorang, yaitu: (1) tingkat utama melaksanakan monabrata, mejagra, dan upawasa, (2) tingkat madya, yaitu mejagra dan upawasa, (3) tingkat nista, yaitu mejagra. Praktek Siwaratri merupakan media proses penyucian, sarana intraksi antara makrokosmos dan mikrokosmos. Siwaratri merupakan simbolisasi dan aktualisasi diri dalam menjalankan spritualitas.

Manusia adalah relasi harmonis dimensi tubuh, akal, roh, dan jiwa menuju kehidupan (Artadi, 2011: 161).
Manusia hidup karena hubungan dengan segala yang melampaui dirinya: orang tua, saudara kandung, tetangga, lingkungan alam, Yang Transenden, dan gaib (Dillistone, 2002: 39). Siwaratri pada hakekatnya merupakan ajaran untuk membangkitkan umat Hindu untuk selalu sadar akan dirinya dan senantiasa intropeksi diri atas perbuatan dosa. Ritual Siwaratri bertujuan memberikan pengetahuan kepada manusia agar menyadari bahwa selalu ada pertarungan antara kebaikan dan keburukan di dalam diri manusia. Siwaratri membangkitkan kesadaran umat Hindu untuk selalu sadar dan berikhtiar kembali ke jalan Dharma dan memperbanyak perbuataan Dharma. Siwaratri mengandung makna penyadaran diri manusia darimana dirinya berasal agar senantiasa mendekatkan diri kepada Tuhan.

Praktik ritual Siwaratri dalam kehidupan umat Hindu merupakan kristalisasi dari konsepsi ideologi ketuhanan yang mereka yakini. Mengutip Dhakidae (2003: 513), pada masa kini agama menjadi perumus identitas, sehingga tidak ada identitas tanpa sumbangan identitas agama di dalamnya. Siwaratri merupakan konter melakukan perlawanan terhadap intoleransi. Keyakinan yang berpola, norma, dan nilai terpadu serta gagasangagasan yang regulatif yang diterima sebagai kenyataan atau kebenaran. 
Ideologi ketuhanan yang diyakini seseorang memberikan gambaran yang koheren mengenai dunianya (Steger, 2005: 7).

Realitas kekinian Siwaratri merupakan titik poin utama bagaimana kita membangun kesadaran diri tidak saja soal realitas ketuhanan namun mencakup realitas hubungan dengan sesama manusia dan lingkungan. Membangun hubungan keselarasan dan harmonis bersama di dunia sebagai "rumah bersama". Mewujudkan "rumah bersama" bagi semua orang untuk merasa merdeka dan damai menjalankan agamanya. Siwaratri dalam skala mikro merupakan kesadaran diri atas realitas tertinggi (Sang Hyang Widhi Wasa/Ranying Hatalla Langit), sedangkan skala makro kesadaran membangun hubungan yang sesuai ajaran dharma dengan manusia lain dan lingkungan. Membangun harmoni dengan sesama manusia yang memiliki perbedaan nilai, sikap, kepercayaan, dan pandangan. Disinilah kontek kesadaran akan pluralism berkembang dalam bentuk multikulture.

\section{Simpulan}

Perayaan Siwaratri merupakan momentum untuk berbenah diri membangun kesadaran, evaluasi dan intropeksi diri. Siwaratri membangkitkan kesadaran umat Hindu untuk selalu sadar dan berikhtiar menjalankan Dharma. Siwaratri memiliki dimensi luas tidak hanya membangun kesadaran diri semata namun termasuk membangun hubungan yang baik dengan sesama manusia yang berbeda nilai, sikap, kepercayaan, dan pandangan.

Dalam setiap tindak intoleran, kehidupanlah yang sesungguhnya sedang dipertaruhkan. Sebab setiap bentuk intoleran dalam beragam bentuk terhadap keyakinan lainnya pada hakikatnya merupakan pengingkaran terhadap kehidupan. Benih-benih intoleran sudah dimulai dari bagaimana mempersepsi sang liyan, kategorikategori yang digunakan untuk menempatkan orang lain dalam kotakkotak kecil identitas yang beku, ketika orang lain tidak lagi diterima dan dihargai dengan segala perbedaannya, melainkan direduksi menjadi sekadar simbol identitas yang dikonstruksi sebagai "orang asing" yang layak disingkirkan.

Agam hendaknya dijadikan sarana untuk mendorong terciptanya multikultur untuk menciptakan budaya perdamian dalam masyarakat. Para pemimpin agama harus menjadikan proritas pembinaan iman umatnya dalam dakwah-dakwah, kotbah-kotbah dan diskusi-diskusi keagamaan lainnya. Toleransi ditanamkan dalam social habit masyarakat.

Langkah awal yang harus 
dilakukan di Indonesia diterapkan dalam komunitas beragama. Masyarakat yang majemuk dan dapat bekerjasama, hidup berdampingan dengan damai, bukan mempertegas dan menonjolkan perbedaan dengan menutup diri. Kunci penciptaan budaya perdamaian dengan menumbuhkan toleransi dan solideritas sosial (persocial behavior), penghargaan dan perlindungan terhadap Hak Asasi Manusia. Maka tiada pilihan selain harus senantiasa berupaya menciptakan hubungan yang toleran, persaudaraan, dan membangun komunikasi lintas agama antar sesama komponen bangsa agar dapat tercipta keharmonisan kehidupan beragama.

\section{Daftar Pustaka}

Abdilah, S. Ubed. 2002. Politik Identitas Etnis Pergulatan Tanpa Identitas. Magelang: Indonesiatera. Artadi, I Ketut. 2011. Kebudayaan Spritual: Nilai Makna dan Martabat Kebudayaan, Dimensi Tubuh Akal Roh dan Jiwa. Denpasar: Pustaka Bali Pos

Campbell, Tom. 1980. Tujuh Teori Sosial: Sketsa, Penilaian, Perbandingan. Yogyakarta: Kanisius.

Dhakidae, Daniel. 2003. Cendikiawan dan Kekuasaan dalam Negara Orde Baru. Jakarta: Gramedia Pustaka Utama.

Dillistone, F.W. 2002. Daya Kekuatan Simbol: The Power of Symbols. (A. Widyamartaya, Pentj). Yogyakarta: Kanisius.
Epstein, Mikhail. 1995. After the Future: The Paradoxes of Postmodernism and Contemporary Russian Culture. Amherst: The University of Massachusetts.

Harker, Richard, Cheelen, dan Chris Wilkes (ed). 2009. (Habitut X Modal + Ranah = Praktik, Pengantar Paling Komperhensif Kepada Pemikiran Pierre Bourdieu. (Pipit Maizier, Pentj). Yogyakarta: Jalasutra.

Hefner, Robert W (ed). 2007. Politik Multikulturalisme: Menggugat Realitas Kebangsaan. Yogyakarta: Impulse dan Kanisius.

Kaler, I Ketut dan Ni Made Wiasti. 2003. "Kerukunan Hidup Antar Umat Beragama Sebuah Proses Adaptasi Menuju Integrasi (Kasus Desa Pengastulan)". Guratan Budaya dalam Persfektif Multikultural: Katurang ri Kalaning Purnabakti Prof. Dr.I Gusti Ngurah Bagus. I Gede Semadi Astra, dkk (penyunting). Denpasar: Fakultas Sastra san Budaya Universitas Udayana.

Megawangi, Ratna, dkk. 2005. Pendidikan Holistik. Cimanggis: Indonesia Heritage Foundation.

Mulyana, Deddy dan Jalaluddin Rakhmat. 2005. Komunikasi Antarbudaya: Panduan Berkomunikasi Dengan OrangOrang Berbeda Budaya. B andung: PT. Remaja Rosdakarya.

Poloma, Margaret M. 2000. Sosiologi Kontemporer. Jakarta: PT Raja Grafindo Persada.

Rudito, Bambang. 2013. Bebetei Uma Kebangkitan Orang Mentawai: Sebuah Etnografi. Yogyakarta: Penerbit Gading dan Indonesia 
Center for Sustainable

Developmen (ICSD).

Sanderson, Stephen K. 2011.

Makrososiologi: Sebuah

Pendekatan Terhadap Realitas

Sosiologi. Jakarta: Rajawali Press.

Sigai, Ervantia Restulita L. 2007. "Rehabilitasi Pascakonflik Etnis Dayak dan Madura di Sampit, Kalimantan Tengah: Sebuah Kajian Budaya". Tesis. Denpasar: Program Pascasarjana Universitas Udayana.

.2016a. "Eksistensi Balian Bawo Dayak Lawangan di Dusun Tengah, Barito Timur, Kalimantan Tengah". Disertasi. D e n p a s a r : P r o g r a m Pasacasarjana Universit as Udayana.

"M u l t i k u l t i r a 1 P r a k s i s Pendidikan Dalam Keluarga Hindu". Satya Widya, Vol (1) Nomor 2: 258-267.

Stavenhagen, Rudolfo.1996. "Education for a Multikultural world", in Jasque Delors (et all), Paris: Learning the treasure within, UNESCO.

Steger, M.B. 2005. Globalisme Bangkitnya Ideologi Pasar. Yogyakarta: Lafad Pustaka.

Suhardi. 2009. Alam-Religi Solideritas Sosial di Papua dan Jawa: Terawang Ant $r$ o $p$ o l o g $i$. Yogyakarta: Program Beastudi Kajian Antarbudaya Pusat Studi Asia Pasifik Universitas Gadjah Mada.

Taylor, Shelley E., L. Anne Peplau, David O. Sears. 2009. Psikologi Sosial. (Tri Wibowo, Pentj). Jakarta: Kencana Prenada Media Group.

Tilaar, H.A.R. 2003. Kekuasaan dan

Pendidikan. Magelang: Indonesiatera. 